\title{
Variation in herbivory along a latitudinal gradient for native and exotic Asteraceae
}

Post-print/Accepted manuscript

Krystal A. Nunes

Colin M. Cassin

Peter M. Kotanen

Nunes, K.A., Cassin, C.M. \& Kotanen, P.M. Plant Ecol (2016) 217: 481. doi:10.1007/s11258-016-0593-x

The final publication is available at Springer via http://dx.doi.org/10.1007/s11258-016-0593-x

\section{HOW TO CITE TSPACE ITEMS}

Always cite the published version, so the author(s) will receive recognition through services that track citation counts, e.g. Scopus. If you need to cite the page number of the TSpace version (original manuscript or accepted manuscript) because you cannot access the published version, then cite the TSpace version in addition to the published version using the permanent URI (handle) found on the record page. 
Final Word Count: 5573

\section{VARIATION IN HERBIVORY ALONG A LATITUDINAL GRADIENT FOR NATIVE AND EXOTIC ASTERACEAE}

Krystal A. Nunes, Colin M. Cassin, and Peter M. Kotanen

Department of Ecology \& Evolutionary Biology

University of Toronto Mississauga

3359 Mississauga Road

Mississauga, ON, L5L 1C6 CANADA

Corresponding Author: Krystal A. Nunes

krystal.nunes@mail.utoronto.ca

Tel: 1-905-828-5304

Fax: 905-828-3792

\section{Acknowledgements}

This research was supported by the Natural Sciences and Engineering Research Council of Canada (NSERC). We would like to thank L. Cassin, L. A. Goodine, L. Hu, A. Kamath, J. O’Connell, and K. Robert for assistance in the field and lab, and Algonquin Provincial Park for permitting access. 


\section{ABSTRACT}

It has long been hypothesized that biotic interactions, including herbivory, are most intense at lower latitudes. However, this generalization has recently been challenged with studies showing that latitudinal gradients in damage may be rarer than previously believed. Additionally, most studies have focused on herbivory of native species, so it remains unknown whether natives and exotics follow similar patterns. This study compares rates of aboveground herbivory of multiple native and non-native Asteraceae across a latitudinal gradient, with a more detailed investigation of a focal exotic, Cirsium arvense. Herbivory of multiple tissue types was quantified for all species across an 815 kilometre transect in Ontario, Canada. The native Asteraceae included in the survey typically experienced a decline in folivory with increasing latitude. Herbivory patterns for the exotic species were less clear; while most experienced high damage at the southernmost site, some also experienced high damage rates at midlatitudes. For the focal species Cirsium arvense, leaf and stem herbivory declined with increasing latitude, although seed damage showed strong regional variation across the invaded range. These results show that latitudinal variation in herbivory is highly dependent on the plant species being investigated, the tissue type being measured, and the type of herbivore(s) causing the damage. In some cases, populations in marginal areas might benefit from reduced damage by some groups of herbivores. In other cases, factors such as the availability of suitable habitat, the biology of specific enemies, and the origin of the host plant may override the influence of latitude on host performance.

\section{KEYWORDS}

Latitudinal gradient, herbivory, plant-insect interactions, Asteraceae, Cirsium arvense

\section{INTRODUCTION}

The level of herbivory experienced by an individual plant has important consequences for its overall performance, and ultimately can influence processes on a larger scale including species distribution patterns and community structure (Huntly 1991; Maron and Crone 2006). Nearly all plant species suffer enemy damage in some form, yet the rate at which a species is subject to damage is not constant throughout its range. Instead, it has long been suggested that biotic interactions, including herbivore pressure, are less intense at higher latitudes (Bolser and Hay 1996; Pennings and Silliman 2005; Salazar and Marquis 2012). Such a latitudinal decline in damage may be due to the existence of fewer suitable environments for enemies at the edge of a plant's range, or the inability of its enemies to 
persist in isolated or marginal host populations (Alexander et al. 2007; Bach 1994; Woods et al. 2012). As a result, plants might experience increased performance due to reduced enemy pressure at higher latitudes. Conversely, it is often predicted that marginal plant populations will perform more poorly due to unfavourable environmental conditions at the range edge (Clausen et al. 1948; Jump and Woodward 2003), the influence of Allee effects in small marginal populations (Sexton et al. 2009), and/or maladaptation to local conditions due to gene flow from core populations (Kirkpatrick and Barton 1997). Thus, there may be opposing forces affecting the performance of plant populations at their northern range edge.

Numerous studies have reported reduced plant damage near a species' latitudinal range limit when compared to populations located closer to the core of its distribution (Alexander et al. 2007; Coley and Aide 1991; Coley and Barone 1996; Schemske et al. 2009; Vaupel and Matthies 2012; Woods et al. 2012). Nonetheless, acceptance of the generalization that herbivory decreases with increasing latitude has been challenged. A meta-analysis conducted by Moles et al. (2011a) suggests that the hypothesis of greater herbivory occurring at lower latitudes is not as strongly supported as previously thought. They found that only $37 \%$ of latitudinal comparative studies included in their analysis showed an increase in herbivory at lower latitudes, and only $16 \%$ of studies detected an increase in chemical defenses at lower latitudes (Moles et al. 2011a). This meta-analysis was supported by a field study led by the same author (Moles et al. 2011b), in which more than 300 species were sampled across six continents for a variety of leaf defense traits (chemical resistance, leaf toughness, nitrogen content, etc.). The study found no support that leaves sourced from lower latitudes are better defended against enemy attack despite this being a long-standing hypothesis (Moles et al. 2011b).

The inconsistency of latitudinal patterns in herbivory reported by these studies indicate that gradients in damage, while they sometimes do occur, may be scarcer than previously believed. An additional complication stems from the fact that most of these studies have focused on herbivory of native species, while few have considered interactions in marginal populations of exotics (but see Harvey et al. 2013; Kambo and Kotanen 2014; Lee and Kotanen 2014). Exotics commonly lose enemies when migrating to new regions, as described by the Enemy Release Hypothesis (Elton 1958; Keane and Crawley 2002; Liu and Stiling 2006; Mitchell et al. 2006; Torchin and Mitchell 2004). However, invaders also acquire a new suite of enemies in the invaded range, as local enemies undergo a host-shift or 
enemies from the original range are accidentally or intentionally introduced (Hatcher and Dunn 2011; Hawkes 2007; Levine et al. 2004). These new enemies are likely to be either generalists (Liu and Stiling 2006) or oligophagous species shared with closely related natives (Dawson et al. 2009; Harvey et al. 2012; Pearse and Hipp 2009), and therefore may be less closely linked to the distribution of their hosts than enemies attacking natives. Consequently, it is uncertain whether rules devised to explain patterns of damage in native species extend to invaders. Instead, it may be that different factors limit the distributions of natives and exotics, and so the rules developed to describe patterns of damage in native populations may fail when applied to non-native species. For instance, it has been proposed that attempts to predict distributions of exotics based on climatic tolerances in their native regions may fail when applied to invaded regions if differences in herbivore attack are not also considered (Bradley et al. 2010; Early and Sax 2014; Van der Putten et al. 2010).

The aim of this study is to document changes in aboveground herbivory along a latitudinal gradient for a suite of species in the Asteraceae family. We also provide preliminary measures of plant performance along this gradient to document whether herbivory and performance co-vary in the field, as might be expected if escape from their usual herbivores represents a significant benefit for their host plants. In addition to providing one of the first comparisons of latitudinal herbivory gradients for multiple natives and non-natives, we also present a more detailed investigation of a focal exotic, Canada thistle (Cirsium arvense). C. arvense was selected for further study since the key herbivores are known, there are specialist herbivores that attack a variety of tissue types, and the investigation of noxious exotic species are a rarity in latitudinal studies of herbivory rates. By investigating multiple related species of both native and exotic origins, we seek to compare how these native and exotic species interact with their enemies along a shared latitudinal gradient, and to determine whether or not they follow shared latitudinal trends.

\section{METHODS}

\section{Study Species}

A candidate set of over 30 commonly occurring species of Asteraceae was compiled prior to initiating the survey. The majority of these species have similar habitat preferences, such as mowed fields, roadside ditches, and other high-disturbance areas; populations surveyed in this study were exclusively found in disturbed areas. Only eight species were found in sufficient abundance throughout our study area (a minimum of 3 sampling locations) to be 
included in the analyses. All of these taxa are common in southern Ontario, and (with the exception of arctic genotypes of the Achillea millefolium complex) reach their range limits in boreal Canada, but also extend well south of our study area; our focus therefore is on areas approaching their northern range limits, not their entire distribution.

Four native species were included in this survey. Eupatorium maculatum commonly occurs across much of Ontario, and is typically found in wet and moist habitats such as roadside ditches and wetlands. Achillea millefolium is a widely distributed species that is common to drier sites, such as roadside deposits of gravel and sand. Both native and exotic genotypes occur in Ontario, with some native genotypes extending far to the north (Warwick and Black 1982); since most regional populations are believed to be native (Voss 1996), allowing for a long history of interactions with native herbivores, we considered this species as native in our analyses. Rudbeckia hirta is a prairie wildflower that is most commonly located in dry disturbed areas including rail lines and roadways. The final native species was Anaphalis margaritacea, a sand-loving species that tolerates a range of habitat from open meadow to forest edge.

Four exotic species were also included in this survey. Sonchus arvensis colonizes a range of habitats; populations in this study were exclusively found along roadsides. Taraxacum officinale and Leucanthemum vulgare are both common exotic species found near high disturbance areas such as meadows, roadsides and lawns. Lastly, Cirsium arvense is a widespread perennial herb that is considered to be one of the worst agricultural weeds in North America (Moore 1975; Tiley 2010). It often is found in disturbed areas, and in this survey, was sampled in fields and along roadways.

C. arvense was investigated in greater detail for three reasons. First, in contrast with the other species surveyed, the herbivore fauna of $C$. arvense is well known, allowing a more informative analysis. Second, since most of the common insects on this plant in southern Ontario are themselves introduced specialist herbivores (Cripps et al. 2011; Moore 1975; Tiley 2010), C. arvense may follow different patterns than exotics which have been primarily colonized by native generalist enemies. Finally, our results provide information on the success of biocontrol agents such as the stem galling fly Urophora cardui, particularly in marginal populations of this weed, where they might have the potential to prevent future spread. 


\section{Multispecies latitudinal survey}

An 815 kilometre transect was surveyed, spanning nearly all of the biomes represented throughout Ontario (Fig. 1). Along this transect five nearly equally spaced sampling regions were selected near Newmarket (44 $\mathrm{N})$, Algonquin Park $\left(45^{\circ} \mathrm{N}\right)$, Temagami $\left(47^{\circ} \mathrm{N}\right)$, Timmins $\left(48^{\circ} \mathrm{N}\right)$, and Moosonee $\left(51^{\circ} \mathrm{N}\right)$. To help compensate for changes in phenology across the latitudinal gradient, each region was surveyed for 4-5 days before travelling north to the next sampling region (Kambo and Kotanen 2014). This was based on the number of frost-free days, as our most southern sampling site experienced frost-free days 4 weeks sooner than our most northern site. Sampling began at the most southern locations on 11 July 2012 and completed in the north on 11 August 2012. A circular boundary with a diameter of 25 kilometres was used to define the extent of each sampling region.

To qualify as a suitable population, a minimum of 100 stems found within a $100 \mathrm{~m}^{2}$ area was required. Once a suitable patch had been identified, 15 stems were selected and assessed for height, number of capitulae, and foliar damage in situ; this approach ensured sampling was comparable for each species despite differences in growth, morphology, or degree of clonality. Plants were selected by taking single strides (approximately 1 metre) along a linear transect through each population and selecting the nearest plant, alternating between the left and right side. Plant height was assessed by measuring the distance from the soil surface to the highest meristem of the plant. Reproductive output was assessed by counting the number of flower heads on each plant. To provide an assessment of the level of foliar damage, 15 leaves were randomly selected along the entire height of the shoot and visually assessed for percent area damaged. In the event a plant produced fewer than 15 leaves, as many leaves as possible were assessed for foliar damage (an average of $13.9 \pm 2.1$ leaves per plant were sampled). Damage estimates were made by a single observer and were classified to the nearest $5 \%$ damage with the exception of $0 \%$ and $1 \%$ damage levels. All types of foliar damage (which consisted of chewing and/or skeletonization for all species) were combined for a single estimate of leaf damage.

\section{Cirsium arvense latitudinal survey}

Fifty-three C. arvense populations were sampled over the same latitudinal gradient as the multispecies surveys (Fig. 
1), but independently of those surveys. Since C. arvense is highly clonal, for this species-specific intensive survey we presumed each patch sampled likely was dominated by a single clone; all data from such a presumed clone (e.g. leaf damage) were averaged before statistical analysis. Male clones were excluded from sampling so that seed predation could be measured. Sampling regions included Mississauga ( $\left.43^{\circ} \mathrm{N}\right)$, Markham $\left(44^{\circ} \mathrm{N}\right)$, Newmarket $\left(44^{\circ}\right.$ $\mathrm{N})$, Huntsville $\left(45^{\circ} \mathrm{N}\right)$, Algonquin $\left(45^{\circ} \mathrm{N}\right)$, Temagami $\left(47^{\circ} \mathrm{N}\right)$, Timmins $\left(48^{\circ} \mathrm{N}\right)$, and Moosonee $\left(51^{\circ} \mathrm{N}\right)$. As with the multispecies latitudinal survey, sampling times were staggered in order to account for climatic differences across space: all sites were sampled between 9 July and 21 August, depending on latitude. Based on the Canadian Climate Normals (1981-2010) station data (http://climate.weather.gc.ca/climate_normals), there is a $5.7^{\circ} \mathrm{C}$ reduction in average mean temperature between our most northern (Moosonee) and southern (Mississauga) sampling locations in both July and August. However, the greatest difference in mean temperature is found in the average daily minimum, with Moosonee reaching minimum temperatures that are $6.9^{\circ} \mathrm{C}$ and $6.5^{\circ} \mathrm{C}$ cooler than Mississauga in July and August respectively. In 2013, two new locations were added (Mississauga and Markham), and Algonquin and Huntsville were re-sampled to provide more data and populations from these sparsely represented regions.

Three forms of herbivory were quantified: leaf damage (by generalist herbivores and the specialist tortoise beetle Cassida rubiginosa), seed parasitism (by the weevil Larinus planus and the fly Terellia ruficauda), and stem galling (by the specialist fly Urophora cardui released as a biocontrol agent); Cassida, Larinus, Terellia, and Urophora all are introduced oligophages. These forms of damage were measured separately since this allows description of multiple feeding guilds, their quantification requires different methods, and different feeding types (leaf vs. stem vs. seed) may have different implications for the host. For up to 10 shoots per population, a leaf was sampled from every $30 \mathrm{~cm}$ section of stem, leading to 3-5 leaves per plant and 425 shoots in total; this procedure ensured even sampling along each stem. Foliar herbivory was quantified as percent area affected, which was determined using visual estimates in the field. All types of foliar damage (mining, hole feeding, skeletonizing, etc.) were combined for a single estimate of leaf damage. A subsample of 372 leaves were re-analyzed in the lab using a $0.5 \mathrm{~cm}$ grid to estimate damage, confirming the accuracy of visual estimates (correlation of visual estimates and grid measurements: $\mathrm{R}^{2}=0.938, \mathrm{y}=0.960 \mathrm{x}+0.139$; Figure $\left.\mathrm{S} 1\right)$. From the same 10 shoots/clone, all flower heads were collected and scored for seed parasitizing insects in the lab. This was done by opening the capitulae and looking for larvae or pupae of seed predators. Capitulae in which the pupae had already emerged but showed evidence of frass, 
seed damage, and exit holes were also classified as parasitized. Finally, stem damage was determined by visually scoring up to 100 shoots per clone for stem galls.

To determine if patterns in herbivory were being driven by leaf tissue quality, 5 leaves from three populations in each sampling location were ground using a $60 \mu \mathrm{m}$ mesh Wiley mill and analysed for carbon and nitrogen content using a CHN elemental combustion system (Costech model ECS 4010). These were the same leaves that were quantified for herbivore damage.

\section{Statistical Analysis}

For the multispecies survey, we chose to analyze results for each species separately, both because different species exhibited different patterns in plant growth and herbivore damage, and because not all species could be located at each site. Sites were compared using one-way ANOVAs; because of limited spatial replication, we compared sites using Tukey HSD tests rather than attempting to fit curves to latitude. For herbivory, we also present results from a generalized linear model of proportion of leaf area damaged using a logit link; since these data are continuous, not binomial, we instead assumed a normal distribution (Warton and Hui 2011). Data did not always meet parametric statistical assumptions; however, nonparametric analyses produced nearly identical results. Significance changed qualitatively in only one case (number of capitulae for Chrysanthemum: ANOVA p = 0.04, Kruskal-Wallis p= 0.11).

Greater replication allowed us to perform more detailed analyses on data from the Cirsium arvense survey, and to

directly estimate the role of latitude. All analyses were performed on clone means. In two locations (Huntsville and Algonquin) some of the presumed same clones were sampled in two years. Since shoots die each winter, we treated these as independent trials. A generalized linear model (GLM) approach was used to analyze these data. Proportional data for the presence of stem galls and seed predators were analysed using a logit link and binomial distribution with correction for overdispersion. Leaf damage data (i.e. the proportion of leaf removed) is nonbinomial, making a normal error model with logit link a more appropriate choice (Warton and Hui 2011). A normal distribution with log link was used for ratio data (i.e. carbon/nitrogen content), and an identity link was used for measurements (i.e. stem height, number of viable seeds). 
All analyses were conducted using JMP 12 (SAS Inc. 2015).

\section{RESULTS}

\section{Multispecies latitudinal survey}

Each of the 8 species surveyed showed differences in leaf damage among sites $(\mathrm{p} \leq 0.0002)$; results of ANOVA and GLM analysis were nearly identical. Not all species responded with the same patterns of damage; however, in most cases, southern populations tended to have relatively high levels of leaf damage (Fig. 2). For the natives, the two southernmost populations (Algonquin Park and Newmarket) always ranked higher in damage than the remaining populations, and a posteriori tests indicated that all species experienced significantly higher levels of damage in one or both of these populations than in more northern populations. For the exotic species, patterns were slightly different: for Chrysanthemum and Cirsium, an intermediate site (Timmins) ranked highly; damage was also high for Algonquin populations of Cirsium, a pattern not seen for this species in the more intense focal sampling (below). Still, for all species except Chrysanthemum, the southernmost site (Newmarket) experienced as much or more damage than more northern sites.

Plant height often differed among populations, though less consistently than patterns of damage. For three of four natives, plants tended to be slightly but significantly taller at more northern sites; for Rudbeckia, this pattern was reversed (Fig. 3). For exotics, plants consistently tended to be tallest at the most southern site (Newmarket), though the ordering and significance of population differences varied among species. For both natives and exotics, number of capitulae per plant varied widely, with few obvious patterns (Fig. S2). Correlations between damage and performance were inconsistent. Leaf damage and performance were negatively correlated for Anaphalis (height vs. damage: $\mathrm{F}_{1,58}=8.64, \mathrm{r}_{\text {adj }}=0.11, \mathrm{p}=0.005$; capitulae vs. damage: $\mathrm{F}_{1,58}=4.54, \mathrm{r}_{\text {adj }}=0.06, \mathrm{p}=0.04$ ) and nearly for Achillea (height $v$ s. damage: $\mathrm{F}_{1,73}=3.34, \mathrm{r}_{\text {adj }}^{2}=0.03, \mathrm{p}=0.07$ ), but there was a weak positive correlation between performance and damage for Rudbeckia (capitulae vs. damage: $\mathrm{F}_{1,58}=6.47, \mathrm{r}_{\text {adj }}^{2}=0.08, \mathrm{p}=0.01$ ) and Sonchus (height vs. damage: $\mathrm{F}_{1,58}=4.10, \mathrm{r}^{2}$ adj $=0.05, \mathrm{p}=0.05$ ).

\section{Cirsium arvense latitudinal survey}


Leaf damage declined significantly with increasing latitude $\left(\chi_{1}^{2}=64.1, \mathrm{p}<0.0001\right.$, Fig. 4). For clones sampled in two years, damage was similar in both; excluding the second year of sampling did not alter the conclusions. The stem-galling fly Urophora cardui was present only in the most southern locations sampled, resulting in a significant decline in galls with increasing latitude $\left(\chi^{2}{ }_{1}=5.93, \mathrm{p}=0.015\right.$; Fig. 4$)$. The proportion of capitulae attacked by insects also differed among sites (Fig. 5). Collectively, damage by insects tended to be highest in the most southerly locations. The fraction of capitulae attacked by the two most prominent seed-attacking insects, the weevil Larinus planus and the fly Terellia ruficauda, did not show a significant pattern with latitude $\left(\chi_{1}^{2}=0.07, \mathrm{p}=0.79\right)$; however, this result conceals contrasting gradients for these two insects. Larinus was significantly more common in southern locations $\left(\chi_{1}^{2}=5.63, \mathrm{p}=0.017\right)$; Terellia was more common at higher latitudes although this pattern was not significant $\left(\chi_{1}^{2}=1.76, \mathrm{p}=0.185\right.$, Fig. 5). For clones sampled in 2012 and 2013, occurrence of seed predators was almost identical in both years; excluding the second year of sampling did not alter the conclusions.

Stem height did not follow a latitudinal trend $\left(\chi^{2}{ }_{1}=2.59, \mathrm{p}=0.1073\right.$; Fig. 6$)$, nor did the number of capitulae produced $\left(\chi_{1}^{2}=3.41, p=0.0647\right.$; Fig. 6$)$. However, the number of viable seeds produced did increase with increasing latitude $\left(\chi_{1}^{2}=4.08, \mathrm{p}<0.0001\right.$, Fig. 6). Plant height and number of capitulae produced showed no correlation with leaf damage (height vs. leaf damage: $\mathrm{F}_{1,58}=0.18, \mathrm{r}^{2}{ }_{\text {adj }}=-0.01, \mathrm{p}=0.68$; capitulae vs. leaf damage: $\left.\mathrm{F}_{1,57}=1.29, \mathrm{r}_{\text {adj }}^{2}=0.005, \mathrm{p}=0.26\right)$, but the number of viable seeds was negatively correlated with both leaf damage $\left(\mathrm{F}_{1,57}=11.58, \mathrm{r}_{\text {adj }}^{2}=0.16, \mathrm{p}=0.001\right)$ and (as might be expected) capitular damage $\left(\mathrm{F}_{1,57}=11.69, \mathrm{r}^{2}\right.$ adj $=0.16, \mathrm{p}=$ 0.001). The mean number of stem galls present was not significantly correlated with any measures of performance. The C:N ratio of leaves did not follow a latitudinal trend $\left(\chi^{2}{ }_{1}=0.13, \mathrm{p}=0.71\right.$; Figure S3), and did not complement the degree of leaf herbivory quantified at each site.

\section{DISCUSSION}

The native Asteraceae included in the survey typically experienced a decline in leaf herbivory at higher latitude, but herbivory patterns for exotic species were less clear. Many exotics experienced high damage rates at low latitudes and mid-latitude sites as well. For the focal species Cirsium arvense, leaf and stem herbivory did decline with 
increasing latitude, although seed damage showed strong regional variation across the invaded range. Patterns in plant performance were unclear for most species, although Cirsium produced more viable seeds at higher latitudes.

\section{Differences in damage between native and exotic Asteraceae}

Patterns in herbivory cannot always be explained by a simple correlation with latitude (Moles et al. 2011a; Moles et al. 2011b), despite this being a recurring theme in the literature (Kozlov 2007; Pennings et al. 2009; Pennings et al. 2007; Vaupel and Matthies 2012; Zhang et al. 2011). Instead, we found latitudinal patterns to be highly dependent on the plant species being investigated. Damage also depended on the tissue type being measured and the type of herbivore(s) causing damage, as seen in Cirsium arvense where patterns of damage differed strikingly between different tissue types. For Oenothera biennis, Anstett et al. (2014) similarly found latitudinal gradients in damage were dependent on the identity of the herbivore.

The native plants included in this survey generally experienced higher levels of leaf herbivory in southern populations than northern populations, as some studies have reported for other natives (Coley and Aide 1991; Pennings et al. 2009; Zhang et al. 2011). Herbivory patterns for the exotic species surveyed were less clear; these species typically experienced high damage rates at lower latitudes, but sometimes experienced high damage rates at mid-latitudes as well, especially in regions such as Timmins where significant agriculture exists. This suggests that exotic species may not always follow the same general trends in rates of folivory as natives, possibly because herbivores of exotics are more likely to be generalists (Liu and Stiling 2006) and therefore are less influenced by the distribution of any single host plant. However, results should be interpreted cautiously due to our limited replication.

Climatic variation across large spatial scales, including reduced air temperature and growing season at higher latitudes, might be expected to cause a decline in plant size as one moves northwards (Jonas et al. 2008; Zhang et al. 2011), though this is not always the case (e.g. Kambo and Kotanen 2014). In our case, exotic plants were typically taller at southern latitudes, but native plants were often taller at northern latitudes (with the exception of Rudbeckia), while our results demonstrated no clear patterns in reproductive output for either native or exotic species. An alternative cause of variation in plant performance could be attributed to variation in enemy pressure, as those species that performed well at higher latitudes often experienced reduced damage rates in these areas, but again this 
hypothesis does not true for all species. Furthermore, a reduction in foliar damage is often inconsequential for overall plant performance (Maron and Vila 2001), further stressing the utility of measuring damage levels on multiple tissue types.

\section{Trends in damage of Cirsium arvense}

For $C$. arvense, a much more detailed dataset allowed better description of latitudinal trends. Plants in southern Ontario were heavily damaged by non-native insects, many of which are specialist herbivores on C. arvense (Cripps et al. 2011). Foliar damage demonstrated a strong negative relationship with latitude unrelated to leaf quality, as indicated by C:N ratio. Instead, the decline in folivory is likely due to a reduction in herbivore populations at higher latitudes, a trend that was qualitatively observed in the field. Although this trend was not clear for all of our exotic species, similar results have been reported for at least one other non-native. For the exotic Arctium minus, Kambo and Kotanen (2014) similarly found a reduction in herbivory with latitude believed to have resulted from declines in herbivore density rather than plant quality, since leaf nitrogen content and measures of physical defenses were unable to explain levels of herbivory. These results were later confirmed through a common garden experiment using the same genotypes of $A$. minus, which found that latitudinal differences in herbivory could not be explained by genotypic differences, but instead are likely a result of herbivore absence at higher latitudes (Lee and Kotanen 2014).

Stem galling was recorded only at the most southern site sampled, although galls were common at this location and occur elsewhere in southern Ontario. Galling is caused by the specialist biocontrol fly Urophora cardui, which is most successful in moist, disturbed areas such as agricultural fields (Frenzel et al. 2000). These conditions were far more common in the southern sampling sites, and so it is possible that northern regions do not provide suitable habitat for $U$. cardui to be successful.

Unlike folivory and stem galling, seed herbivory did not follow a latitudinal pattern but instead showed strong regional variation. Pre-dispersal seed predation was frequent in southern Ontario, declined significantly in central Ontario populations, and then once again increased in the north. This pattern was associated with a transition in the type of seed predator with increasing latitude. Seed predation in southern Ontario populations was generally caused 
by the specialist weevil Larinus planus, whereas in the north, seeds were attacked by the specialist fly Terellia ruficauda. These trends might reflect the poor competitive ability of T. ruficauda (Angermann 1986). Following the introduction of L. planus into North America, T. ruficauda has become a fugitive species as it has been extirpated from the southern region of multiple provinces (Lalonde 1991). A second possible cause of this pattern could be due to variability in the population dynamics of $C$. arvense across the surveyed region. Populations of $C$. arvense in central Ontario were smaller and more isolated than elsewhere in the province. Small populations are often unable to support large herbivore populations, and are also more difficult for herbivores to initially locate (Feeny 1976); therefore, the lack of seed parasitism in these $C$. arvense populations could be due to the fact that they did not satisfy a critical host abundance required by these herbivores (Sexton et al. 2009; Vaupel and Matthies 2012).

\section{Consequences for performance and range limits}

The performance of marginal populations of both natives and exotic plants may be influenced by opposing forces. It is often predicted that marginal populations will perform more poorly due to unfavourable environmental conditions at the range edge (Clausen et al. 1948; Jump and Woodward 2003), the influence of Allee effects (Sexton et al. 2009), or maladaptation due to gene flow from core populations (Kirkpatrick and Barton 1997). However, they may also experience increased performance due to reduced enemy pressure at northern latitudes; for example, Kambo and Kotanen (2014) found much greater viable seed production in northern populations of Arctium minus as a result of lower rates of attack by the moth Metzneria lappella. We found no consistent evidence for either hypothesis. In the multi-species survey, no significant patterns in capitular output were found for native or exotic Asteraceae; some variation in plant size was found across latitude, but these trends were weak, inconsistent, and varied among species. Both positive and negative correlations between herbivory and performance were observed. These results suggest that any potential benefit of escape from herbivory at marginal locations may have been masked in this dataset by uncontrolled differences among sites, including non-latitudinal variation in the herbivore populations themselves; more thorough sampling (e.g., Kambo and Kotanen 2014) and field experiments (e.g., Lee and Kotanen 2014) would be required to fully address this issue. As well, trends in both herbivory and plant performance also might have been stronger had we sampled across the entire range of these species rather than focussing on their northern distributions. For the focal species Cirsium arvense, again no consistent pattern was found in plant size or capitular output across the latitudinal gradient; however, the number of viable seeds produced was greatest at higher latitudes. 
This pattern is not a simple result of enemy release at northern latitudes as seen in Kambo and Kotanen (2014), since pre-dispersal seed predation was high in both southern and northern C. arvense populations. Larson et al. (2005) similarly found that attack by pre-dispersal seed predators did not affect the per capitulum seed yield of $C$. arvense. A number of other factors may be contributing to this pattern, such as selection for greater seed production at the invasion front (e.g. Darling et al. 2008).

Since plant performance did not consistently decline with latitude, the factors limiting further range expansion of exotics, including the focal species Cirsium arvense, remain unclear. This species does occur somewhat north of our sampling area, so it may be that declines in performance do eventually occur. Alternatively, lack of suitable habitat in northern Ontario may limit future spread of this invader, as $C$. arvense prefers disturbed habitats and rich agricultural soils (Moore 1975; Tiley 2010), conditions which are rarer in the north (Baldwin et al. 2000). However, we found some evidence of increased performance of this species in northern sites, which will likely be amplified under the conditions of a warming climate. Growth chamber experiments have shown that $C$. arvense is expected to experience improved growth and performance under conditions of warming temperatures and increased carbon dioxide levels, suggesting that the range edge of this invader may continue to spread northwards (Ziska et al. 2004).

Together, our results add evidence that the long-standing hypothesis of increased herbivore pressure at lower latitudes is likely an oversimplification of more complex plant-herbivore interactions. Although such declines can occur, as we found for C. arvense, patterns vary among even closely related species. Factors such as the availability of suitable habitat, the biology of specific enemies, and the origin of the host plant often may override the influence of latitude.

Funding: This study was funded by the Natural Sciences and Engineering Research Council of Canada (NSERC). Conflict of Interest: The authors declare that they have no conflict of interest. 


\section{REFERENCES}

Alexander HM, Price S, Houser R, Finch D, Tourtellot M (2007) Is there reduction in disease and pre-dispersal seed predation at the border of a host plant's range? Field and herbarium studies of Carex blanda Journal of Ecology 95:446-457 doi:10.1111/j.1365-2745.2007.01228.x

Angermann HJ (1986) Ecological differentiation of the Tephritid flies Xyphosia miliaria and Orellia ruficauda (Diptera: Tephritidae) in the flower heads of Canada thistle (Cirsium arvense) Entomologia Generalis 11:249-261

Anstett DN, Naujokaitis-Lewis I, Johnson MTJ (2014) Latitudinal gradients in herbivory on Oenothera biennis vary according to herbivore guild and specialization Ecology 95:2915-2923

Bach CE (1994) Effects of a specialist herbivore (Altica subplicata) on Salix cordata and sand dune succession Ecological Monographs 64:423-445

Baldwin DJB, Desloges JR, Band LE (2000) Physical Geography of Ontario. In: Perera AH, Euler DE, Thompson ID (eds) Ecology of a Managed Terrestrial Landscape: Patterns and Processes of Forest Landscapes in Ontario. University of British Columbia Press, Vancouver, British Columbia,

Bolser RC, Hay ME (1996) Are tropical plants better defended? Palatability and defenses of temperate vs. tropical seaweeds Ecology 7:2269-2286

Bradley BA, Blumenthal DM, Wilcove DS, Ziska LH (2010) Predicting plant invasions in an era of global change Trends in ecology \& evolution 25:310-318 doi:10.1016/j.tree.2009.12.003

Clausen JD, Keck D, Hiesey WM (1948) Experimental studies on the nature of species. III. Environmental responses of climatic races of Achillea. Carnegie Institute of Washington, Washington, DC

Coley PD, Aide TM (1991) Comparison of herbivory and plant defenses in temperate and tropical broad-leaved forests. In: Price PW, Lewinsohn TM, Fernandes GW, Benson WW (eds) Plant-Animal Interactions: Evolutionary Ecology in Tropical and Temperate Regions. Wiley and Sons, New York, pp 25-49

Coley PD, Barone JA (1996) Herbivory and plant defenses in tropical forests Annual Review of Ecology and Systematics 27:305-335

Cripps MG, Gassmann A, Fowler SV, Bourdôt GW, McClay AS, Edwards GR (2011) Classical biological control of Cirsium arvense: lessons from the past Biological Control 57:165-174 doi:10.1016/j.biocontrol.2011.03.011 
Darling E, Samis KE, Eckert CG (2008) Increased seed dispersal potential towards geographic range limits in a Pacific coast dune plant The New Phytologist 178:424-435 doi:10.1111/j.1469-8137.2007.02349.x

Dawson W, Burslem DFRP, Hulme PE (2009) Herbivory is related to taxonomic isolation, but not to invasiveness of tropical alien plants Diversity and Distributions 15:141-147 doi:10.1111/j.1472-4642.2008.00527.x

Early R, Sax DF (2014) Climatic niche shifts between species' native and naturalized ranges raise concern for ecological forecasts during invasions and climate change Global Ecology and Biogeography 23:1356-1365 doi:10.1111/geb.12208

Elton CS (1958) The ecology of invasions by animals and plants. The ecology of invasions by animals and plants. John Wiley and Sons, Inc., New York

Feeny P (1976) Plant apparency and chemical defense. In: Wallace JW, Mansell RL (eds) Recent advances in phytochemistry. Plenum Press, New York, pp 1-40

Frenzel M, Eber S, Klotz S, Brandl R (2000) Ecological comparisons across geographical distributions: the thistle gall fly Urophora cardui (Diptera: Tephritidae) on two different Cirsium hosts European Journal of Entomology 97:183-189

Harvey KJ, Nipperess DA, Britton DR, Hughes L (2012) Australian family ties: does a lack of relatives help invasive plants escape natural enemies? Biological Invasions 14:2423-2434 doi:10.1007/s10530-012-02394

Harvey KJ, Nipperess DA, Britton DR, Hughes L (2013) Does time since introduction influence enemy release of an invasive weed? Oecologia 173:493-506 doi:10.1007/s00442-013-2633-8

Hatcher MJ, Dunn AM (2011) Parasites in ecological communities: from interactions to ecosystems. Cambridge University Press, Cambridge

Hawkes CV (2007) Are invaders moving targets? The generality and persistence of advantages in size, reproduction, and enemy release in invasive plant species with time since introduction The American Naturalist 170:832843 doi:10.1086/522842

Huntly N (1991) Herbivores and the dynamics of communities and ecosystems Annual Review of Ecology and Systematics 22:477-503 doi:10.1146/annurev.es.22.110191.002401

Jonas T, Rixen C, Sturm M, Stoeckli V (2008) How alpine plant growth is linked to snow cover and climate variability Journal of Geophysical Research 113 doi:10.1029/2007jg000680 
Jump AS, Woodward FI (2003) Seed production and population density decline approaching the range-edge of Cirsium species New Phytologist 160:349-358 doi:10.1046/j.1469-8137.2003.00873.x

Kambo D, Kotanen PM (2014) Latitudinal trends in herbivory and performance of an invasive species, common burdock (Arctium minus) Biological Invasions 16:101-112 doi:10.1007/s10530-013-0506-z

Keane RM, Crawley MJ (2002) Exotic plant invasions and the enemy release hypothesis Trends in Ecology and Evolution 17:164-170

Kirkpatrick M, Barton NH (1997) Evolution of a species' range The American Naturalist 150:1-23

Kozlov MV (2007) Losses of birch foliage due to insect herbivory along geographical gradients in Europe: a climate-driven pattern? Climatic Change 87:107-117 doi:10.1007/s10584-007-9348-y

Lalonde RG (1991) Oviposition behavior of Orellia ruficauda on Canada thistle. Dissertation, Simon Fraser University

Larson GE, Wittig TA, Higgins KF, Turnipseed B, Gardner DM (2005) Influence of biocontrol insects on Canada thistle: seed production, germinability, and viability The Prairie Naturalist 37:85-100

Lee Y, Kotanen PM (2014) Differences in herbivore damage and performance among Arctium minus (burdock) genotypes sampled from a geographic gradient: a common garden experiment Biological Invasions doi:10.1007/s10530-014-0737-7

Levine JM, Adler PB, Yelenik SG (2004) A meta-analysis of biotic resistance to exotic plant invasions Ecology letters 7:975-989 doi:10.1111/j.1461-0248.2004.00657.x

Liu H, Stiling P (2006) Testing the enemy release hypothesis: a review and meta-analysis Biological Invasions 8:1535-1545 doi:10.1007/s10530-005-5845-y

Maron JL, Crone E (2006) Herbivory: effects on plant abundance, distribution and population growth Proceedings of the Royal Society B 273:2575-2584 doi:10.1098/rspb.2006.3587

Maron JL, Vila M (2001) When do herbivores affect plant invasion? Evidence for the natural enemies and biotic resistance hypotheses Oikos 95:361-373

Mitchell CE et al. (2006) Biotic interactions and plant invasions Ecology Letters 9:726-740 doi:10.1111/j.14610248.2006.00908.x

Moles AT, Bonser SP, Poore AGB, Wallis IR, Foley WJ (2011a) Assessing the evidence for latitudinal gradients in plant defence and herbivory Functional Ecology 25:380-388 doi:10.1111/j.1365-2435.2010.01814.x 
Moles AT et al. (2011b) Putting plant resistance traits on the map: a test of the idea that plants are better defended at lower latitudes New Phytologist 191:777-788 doi:10.1111/j.1469-8137.2011.03732.x

Moore RJ (1975) The biology of Canadian weeds. 13. Cirsium arvense (L.) Scop. Canadian Journal of Plant Science 55:1033-1048

Pearse IS, Hipp AL (2009) Phylogenetic and trait similarity to a native species predict herbivory on non-native oaks Proceedings of the National Academy of Sciences of the United States of America 106:18097-18102 doi:10.1073/pnas.0904867106

Pennings SC, Ho CK, Salgado CS, Wieski K, Dave N, Kunza AE, Wason EL (2009) Latitudinal variation in herbivore pressure in Atlantic Coast salt marshes Ecology 90:183-195

Pennings SC, Silliman BR (2005) Linking biogeography and community ecology: latitudinal variation in plantherbivore interaction strength Ecology 86:2310-2319

Pennings SC et al. (2007) Latitudinal variation in plant-herbivore interactions in European salt marshes Oikos 116:543-549 doi:10.1111/j.2007.0030-1299.15591.x

Salazar D, Marquis RJ (2012) Herbivore pressure increases toward the equator PNAS 109:12616-12620

Schemske DW, Mittelbach GG, Cornell HV, Sobel JM, Roy K (2009) Is there a latitudinal gradient in the importance of biotic interactions? Annual Review of Ecology, Evolution, and Systematics 40:245-269 doi:10.1146/annurev.ecolsys.39.110707.173430

Sexton JP, McIntyre PJ, Angert AL, Rice KJ (2009) Evolution and ecology of species range limits Annual Review of Ecology, Evolution, and Systematics 40:415-436 doi:10.1146/annurev.ecolsys.110308.120317

Tiley GED (2010) Biological Flora of the British Isles: Cirsium arvense (L.) Scop Journal of Ecology 98:938-983 doi:10.1111/j.1365-2745.2010.01678.x

Torchin ME, Mitchell CE (2004) Parasites, pathogens, and invasions by plants and animals Frontiers in Ecology and the Environment 2:183-190

Van der Putten WH, Macel M, Visser ME (2010) Predicting species distribution and abundance responses to climate change: why it is essential to include biotic interactions across trophic levels Philos Trans R Soc Lond B Biol Sci 365:2025-2034 doi:10.1098/rstb.2010.0037

Vaupel A, Matthies D (2012) Abundance, reproduction, and seed predation of an alpine plant decrease from the center toward the range limit Ecology 93:2253-2262 
Voss EG (1996) Michigan Flora Part III. University of Michigan Press, Ann Arbor.

Warton DI, Hui FKC (2011) The arcsine is asinine: the analysis of proportions in ecology Ecology 92:3-10

Warwick SI, Black L (1982) The biology of Canadian weeds. 52. Achillea millefolium L. s.l. Canadian Journal of Plant Science 62: 163-182.

Woods EC, Hastings AP, Turley NE, Heard SB, Agrawal AA (2012) Adaptive geographical clines in the growth and defense of a native plant Ecological Monographs 82:149-168

Zhang Y, Adams J, Zhao D (2011) Does insect folivory vary with latitude among temperate deciduous forests? Ecological Research 26:377-383 doi:10.1007/s11284-010-0792-1

Ziska LH, Faulkner S, Lydon J (2004) Changes in biomass and root:shoot ratio of field-grown Canada thistle (Cirsium arvense), a noxious, invasive weed, with elevated $\mathrm{CO}^{2}$ : implications for control with glyphosate Weed Science 52:584-588 doi:10.1614/ws-03-161r 
Fig. 1 A map of Ontario, Canada indicating all sampling sites. Not all species were sampled at each site; sites marked with a circle indicate locations where only C. arvense was sampled.

Fig. 2 Patterns of leaf damage in study species; box plots indicate mean (dot), quartiles, and 1st and 9th deciles; error bars represent standard error. Locations are ordered by increasing latitude; Newmarket (NEW), Algonquin (ALG), Temagami (TEM), Timmins (TIM), and Moosonee (MOO. Data were not collected at locations lacking boxes. Shown are results of a one-way ANOVA (F) and a GLM $\left(\chi^{2}\right)$ with groupings identified by Tukey HSD multiple comparisons; locations sharing the same subscript letter do not differ significantly $(\mathrm{p}>0.05)$.

Fig. 3 Patterns of plant height in study species; box plots indicate mean (dot), quartiles, and 1st and 9th deciles; error bars represent standard error. Locations are ordered by increasing latitude; Newmarket (NEW), Algonquin (ALG), Temagami (TEM), Timmins (TIM), and Moosonee (MOO). Data were not collected at locations lacking boxes. Shown are results of a one-way ANOVA with groupings identified by Tukey HSD multiple comparisons; locations sharing the same subscript letter do not differ significantly ( $\mathrm{p}>0.05)$.

Fig. 4 Patterns of leaf and stem damage in Cirsium arvense. Data points are clone means; $N=58$ clones. (a) Mean leaf damage versus latitude; (b) proportion of shoots with stem galls versus latitude. Lines indicate significant regressions.

Fig. 5 Patterns of pre-dispersal seed predation in Cirsium arvense. Data points are clone means; $N=57$ clones. (a) All seed predators; (b) capitulae infested by Larinus planus; (c) capitulae infested by Terellia ruficauda. Lines indicate significant regression for (b), but nonsignificant trends for (a) and (c).

Fig. 6 Measures of performance for Cirsium arvense. Data points are clone means; N = 58 clones; (a) stem height; (b) mean number of capitulae per shoot; (c) mean number of viable seeds per capitulum. Lines indicate significant regression for (c), but nonsignificant trends for (a) and (b). 


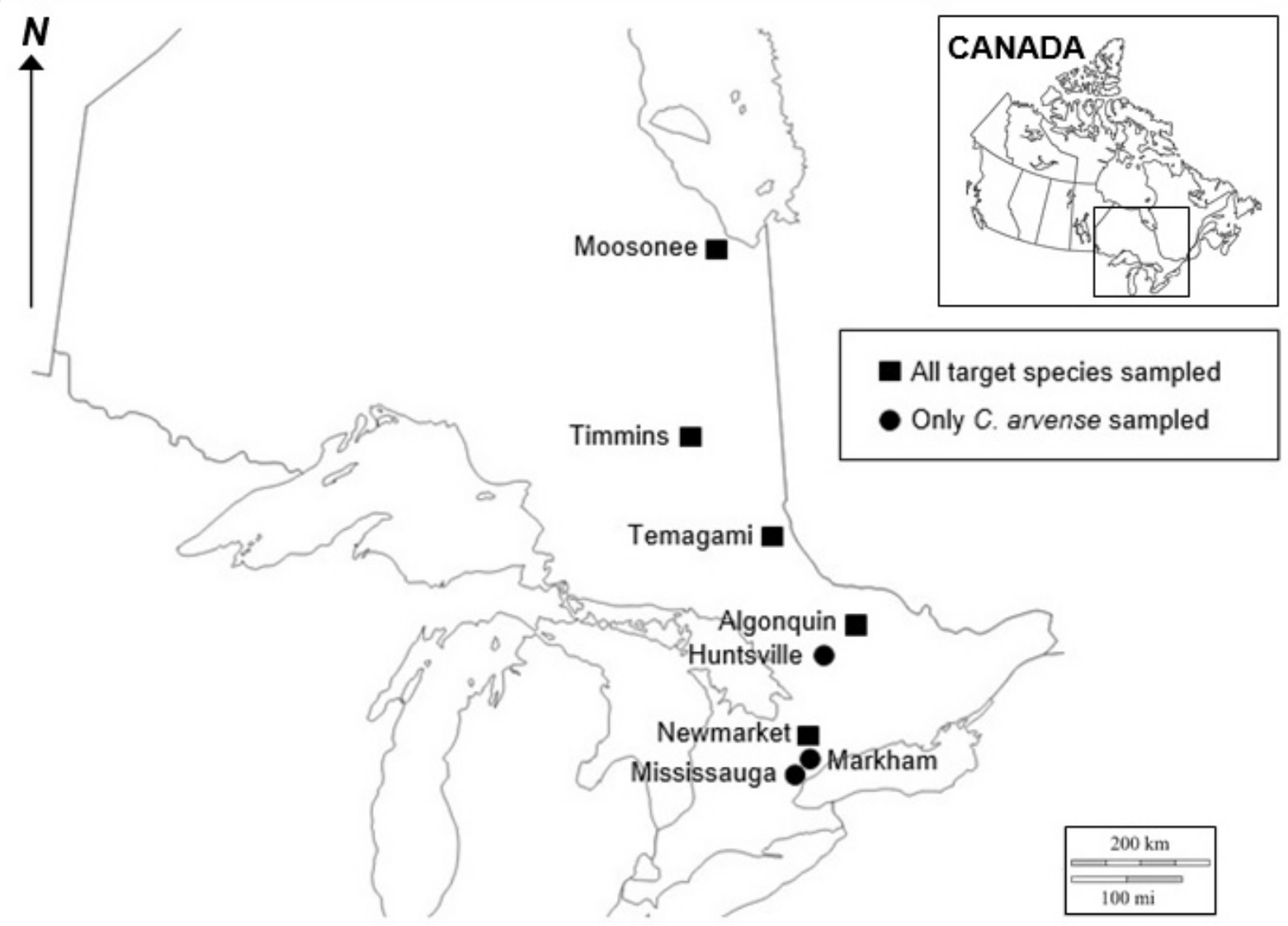



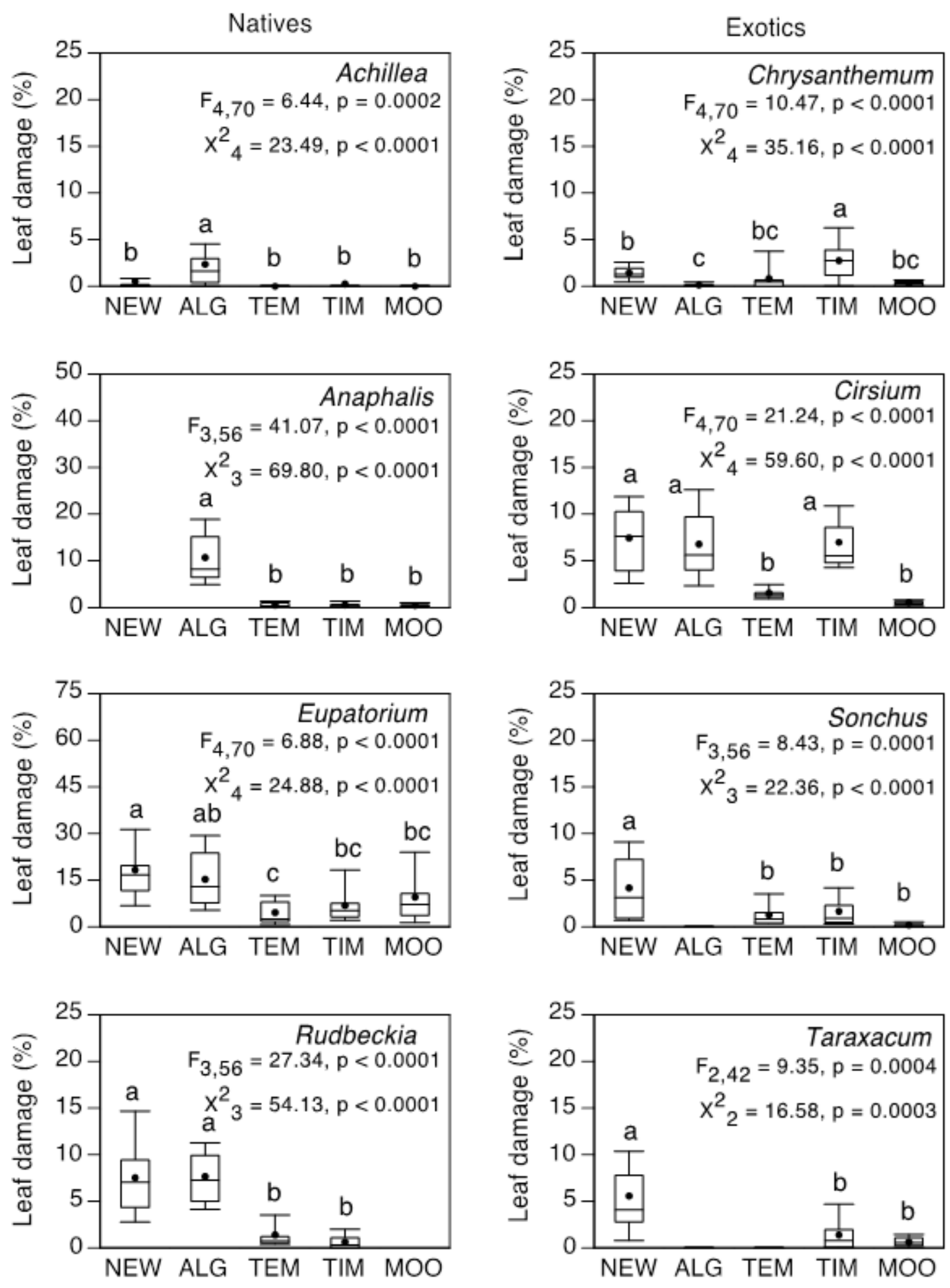

Sampling location 

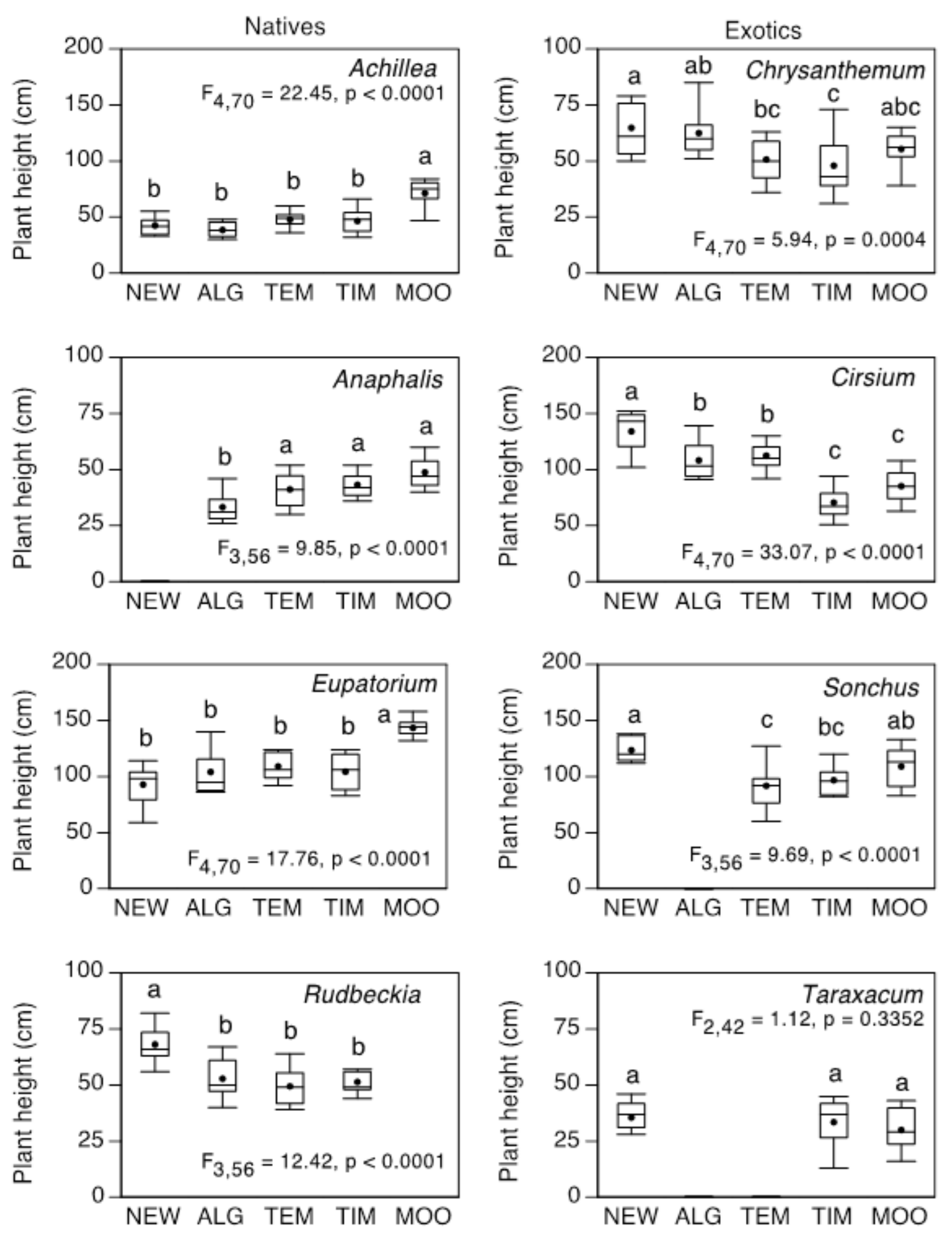

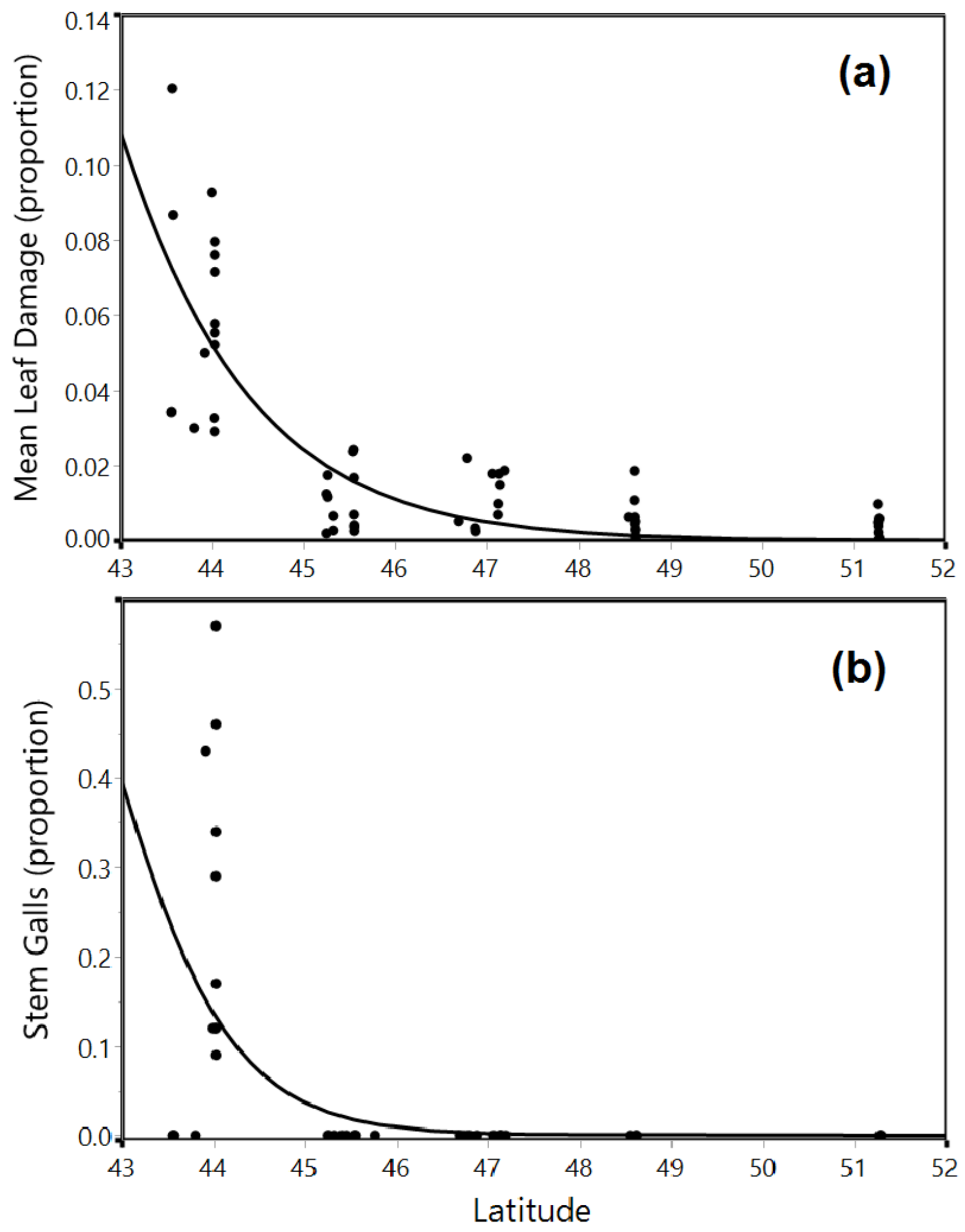

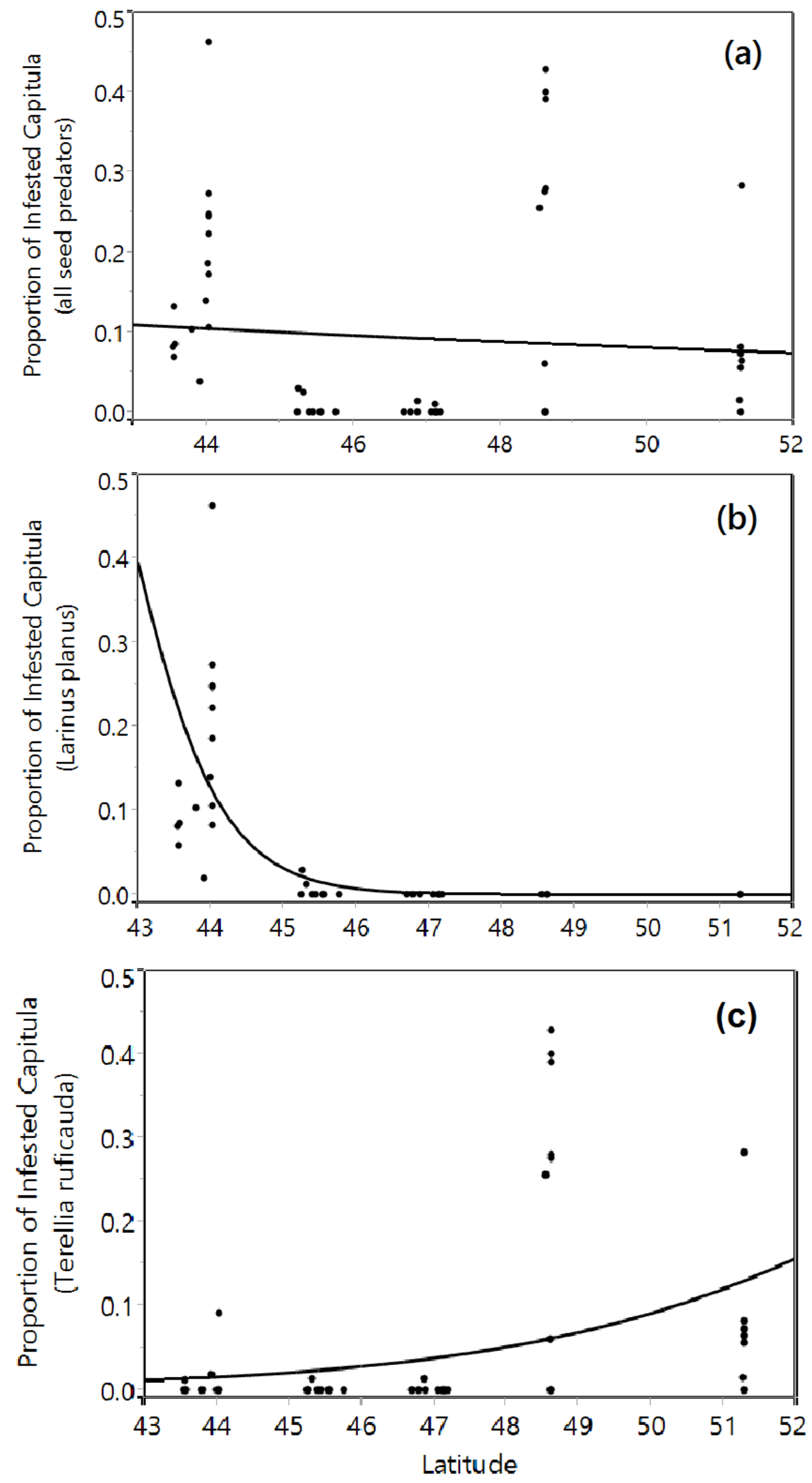

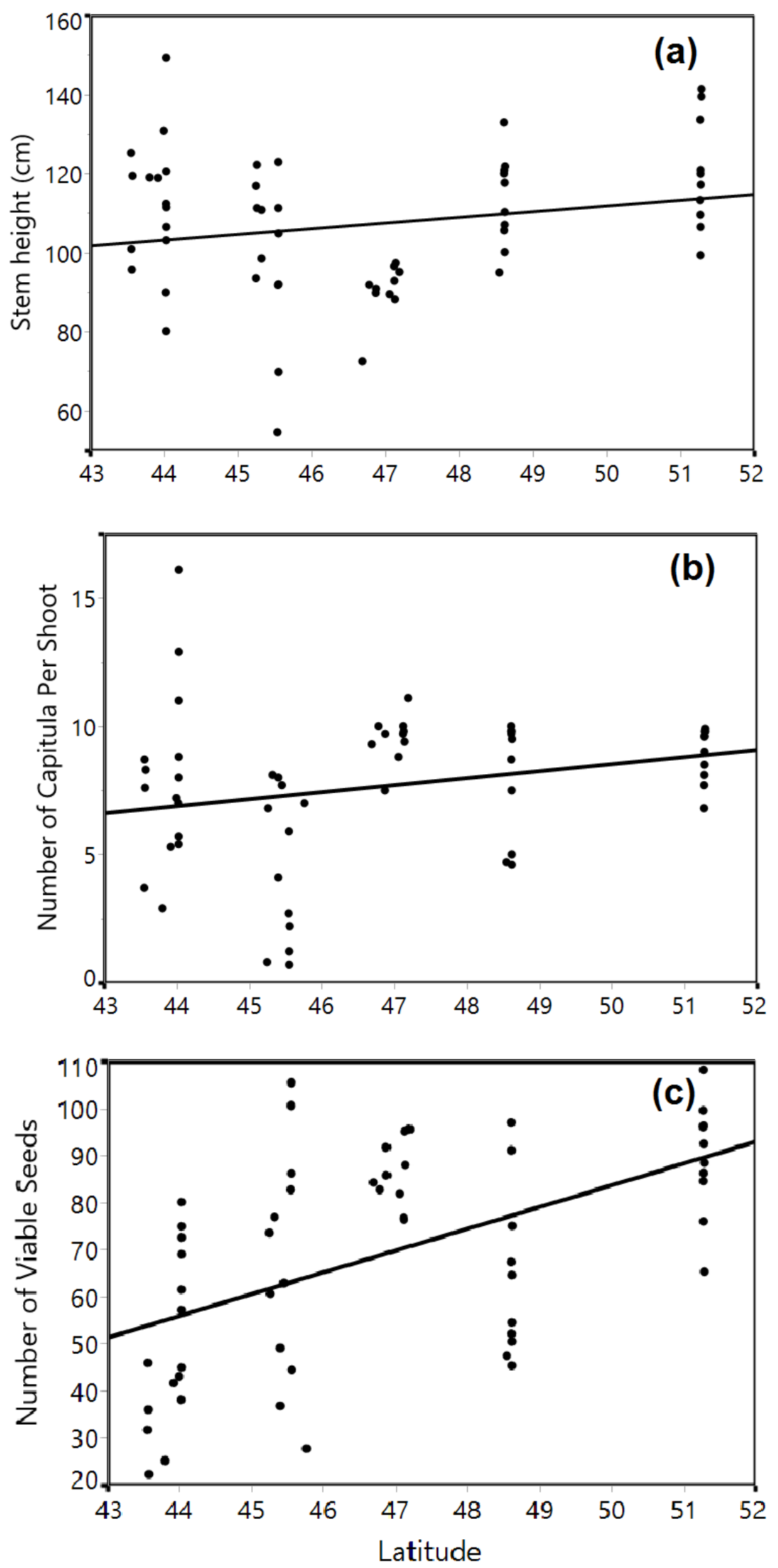